\title{
PLM as Support for Global Design Reuse - Long Term Benefits and Immediate Drawbacks
}

\author{
Christoffer Levandowski, Mattias Bokinge, \\ Johan Malmqvist, and Hans Johannesson \\ Department of Product and Production Development, \\ Chalmers University of Technology, Gothenburg, Sweden \\ \{levandow, bokinge, joma, hansj\} @chalmers.se
}

\begin{abstract}
To stay competitive, a large company must make use of its size and gain economy of scale, one way being through reusing designed parts and technology knowledge globally throughout the organization.

This paper describes a case study performed at a company that is implementing a new Product Lifecycle Management (PLM) system, globally across several different divisions, to be able to reuse design across the organization.

The study shows that though global design reuse is the final goal, the way there is long. The true benefits are still in the future, but there are issues with the PLM solution on the designer level. To prevent such a situation in the future, the authors suggest that benefits shall be defined for all phases in the PLM implementation, not just as high business goals for the final stage. That way, you keep momentum in the change effort and keep all parties motivated.
\end{abstract}

Keywords: PLM implementation, design reuse, case study.

\section{Introduction}

Depending on the size of a company, different benefits may be harvested. A small company must for example use its agility in order to be able to counter their larger competitors. A large company may instead make use of its size and gain economy of scale. Reusing design and knowledge throughout the organization is proven to be very beneficial [1-3]. The benefits are numerous, for example divisions can reuse design from other divisions, resources can be shared across markets, manufacturing equipment can be used for larger series, purchase can get discounts when buying huge numbers of parts.

Though global design reuse promises a lot, it also requires a great effort from the company. It requires a platform consisting of processes, information, tools and people working together [4] to reuse design and design for reuse. Product Lifecycle Management (PLM) is a business approach that promises just that [5]. The success of PLM has however been debated and can often be derived to poor implementation of the PLM solution [6].

This paper describes a case study at a multi-national organization that is in the middle of implementing PLM to support global design reuse. GlobalCorp (masked 
name) consists of over 150 subsidiaries, divided into eight different business areas working all across the globe. They have decided that they will use Product Lifecycle Management to support a structured way of doing business, a way to collaborate across the globe and to facilitate reuse of designed parts throughout the organization.

\subsection{Theory of Design Reuse}

One way of reusing design is to have a platform to derive products from. Robertson and Ulrich [3] define a product platform as the collected assets shared by a family of products - an asset being a component, subsystem, process, technology or even a person. Another definition, a bit less abstract, is the one provided by Meyer and Lehnerd [1], which states that a product platform is "a set of subsystems and interfaces developed to form a common structure from which a stream of derivative products can be efficiently developed and produced". Meyer and Lehnerd's [1] definition encompasses the view of a platform as a set of parts that are shared throughout the organization to make the design effort more efficient, similar to the view of Kota \& Sethuraman [7]. Although several studies have been done in how to define product families, the area of PLM support for design reuse is still not fully formed.

\subsection{The Concept of PLM in Relation to Design Reuse}

PLM is a business approach that promises to solve several of the issues with global cooperation. PLM can be defined as the activity of managing the product from the very first idea to the disposal of it, according to Stark [8] - this approach gives a process oriented definition of the term.

Although several system vendors often speak of their system and PLM synonymously, PLM are more than just a system, or a set of systems. Zimmerman [9] identifies different layers of a PLM architecture, as shown in figure Fig. 1, where the system architecture is one of seven layers.

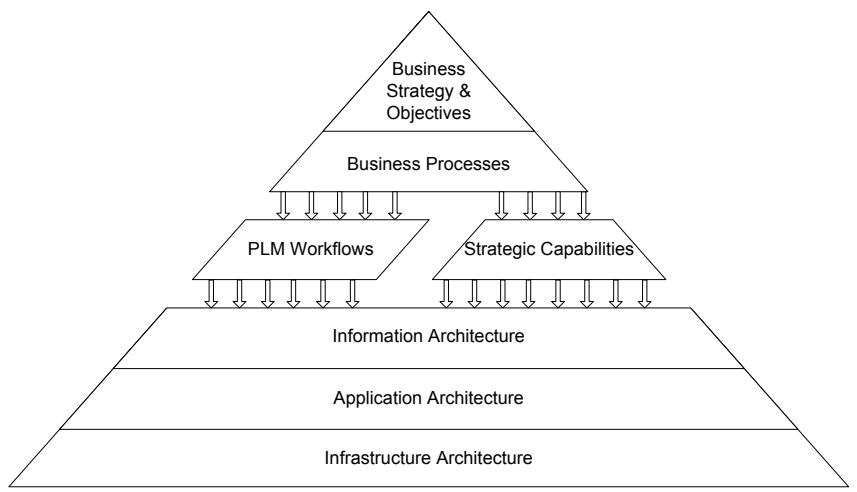

Fig. 1. Different layers of a PLM architecture (redrawn from Zimmerman [9]) 
Stark [8], and also Sudarsan [10], describe a PLM system as a technology that realizes PLM functionality, but is clear on that no PLM system can encompass all PLM functionality. Furthermore, in comparison to relating systems, such as Computer Aided Design (CAD) and Enterprise Resource Planning (ERP), PLM systems are still immature [8].

Supporting design reuse through PLM is an area covered from many angles. Eppinger [11] highlights the mutual relationship between global collaboration and modularization as a way to share knowledge and technology across different locations. In another paper [12], he stresses the information flow powered by PLM as a means to collaborate, and share knowledge in product development. Related to that, product configuration - how to combine different sub systems into a product - is a common way to realize design reuse. Simpson [13] pinpoints several design automation supports through reusing design. For more abstract representations of design knowledge, wiki solutions have been suggested to support design reuse [14].

The poor performance of PLM systems has been debated and has in many cases been concluded to be the result of poor implementation[6]. Several studies have therefore come up with guidelines to use in the process of implementation [15] to ensure success and fulfillment of the goals. Studies on guidelines for implementing PLM for design reuse are sparse in their numbers. Studies $[8,16]$ do however show that global design collaboration in more general terms is facilitated through PLM.

\subsection{Paper Outline}

The study has focused on benefits on the way towards global design reuse through a global PLM strategy, and how these benefits are affected by drawbacks from the same strategy. The paper is disposed as follows: section 2 gives a deeper understanding of the scope of the study, whereas section 3 puts forward the research questions of the paper and the methods used to answer them. In section 4 the results are disclosed, followed by a discussion and analysis of the results (section 5). The paper, with its most important points, is concluded in section 6.

\section{Case Setting}

This section describes the scope of the case study. The case description is based on information received through the interview study described in section 3 . The studied company, GlobalCorp, is a multi-national company with over 150.000 employees and more than 200 manufacturing sites around the world. GlobalCorp have grown over the years through numerous acquisitions, resulting in a myriad of standalone subsidiaries. Until recently, they let each division operate as standalone companies. However, the fierce competition has inspired GlobalCorp to start thinking about leveraging the size of their company to gain economies of scales in purchasing, operations and design across divisions. One major part of the path towards fully utilizing the size of the company is to introduce a global PLM strategy. GlobalCorp have chosen one vendor to supply them with a PLM system to realize the strategy for the entire organization.

At the corporate level, there is a governing organization that coordinates work between the different divisions. This is also where the global strategies are set. On the 
PLM side, GlobalCorp PLM Centre of Excellence (COE) is responsible for setting strategies, acting both as a supporting organization for the divisions, but also as governance for the PLM implementations. The division level has typically several companies under them, which are often also spread across multiple sites all over the world, working at different markets. In addition to the global PLM COE, the local divisions govern their PLM implementation.

\section{$3 \quad$ Research Questions and Method}

The case described above provides a good setting for studying benefits and drawbacks in a PLM implementation. Literature does not cover the expected benefits on the way towards design reuse, through support of PLM, what benefits to expect from a global PLM strategy, let alone when they are to be expected. Thus, given that context, three research questions have been defined:

- What constitutes a PLM solution for global design reuse (GDR)?

- What benefits and drawbacks are there with a PLM solution for GDR?

- What benefits from a PLM solution for GDR can be harvested early and which are more long term?

- What obstructions are there to jeopardize future predicted benefits, and how may they be overcome?

\begin{tabular}{|c|c|c|c|c|}
\hline & GlobalCorp & $\begin{array}{c}\text { Global } \\
\text { Measuring }\end{array}$ & $\begin{array}{l}\text { Global } \\
\text { Cooling }\end{array}$ & $\begin{array}{l}\text { Global } \\
\text { Electric }\end{array}$ \\
\hline Center of Excellence & मीय & $\hat{n}$ & $\hat{n}$ & \\
\hline Local PLM & & भी & $\lambda$ & 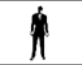 \\
\hline Designers & & ong & is & is \\
\hline
\end{tabular}

Fig. 2. Interview sample in the study. In total, 17 interviews were performed.

The answer to the research questions above was sought through an interview study at GlobalCorp where 17 interviews were performed. Two different roles (Designer and Local PLM manager), at three different divisions where interviewed, along with PLM strategists at GolbalCorp COE.

The interviews were semi-structured interviews [17], one to two hours long, where open ended questions were asked, to have the interviewees in their own words explain and elaborate on an answers for the prepared questions. It is common that the research questions take their final form first after some data has been collected to avoid answering the wrong question [18]. The interviews were transcribed, and verified with the interviewees. The result was presented to design engineers and PLM staff at GlobalCorp, after the analysis was done, as a part of the validation [19]. Multiple sources (group discussions, interviews and email) was used to achieve construct validity. 


\section{$4 \quad$ Findings}

The result of the interviews is divided into three sections. The first, PLM architecture for global design, describes the solution that GlobalCorp chose, to provide them with PLM functionality. The second section maps design reuse enablers to the implementation roadmap. Thirdly, a list with benefits and drawbacks that the organization has experienced so far is presented.

\subsection{PLM Architecture for Global Design Reuse}

The result of the interviews inevitably point towards a strong aim of leveraging the size of the company to gain advantages in several areas, where reusing design is the major one. There are several different aspects of design reuse identified at GlobalCorp, the major part of course being reuse of designed parts, or elements in places where it was not originally designed. Since GlobalCorp is spread out across the world, design reuse becomes global design reuse. The majority of the respondents stated that their respective division does in fact cooperate with other companies within their own division quite frequently. It is also desirable to, in the future, cooperate closer with other divisions and share designed parts. The solution described below is common for all divisions within GlobalCorp and originates from the PLM strategists at GobalCorp COE.

Business Goals. The main driver for implementing one PLM system is to have a global platform for collaboration, when it comes to product design. GlobalCorp simply want to leverage its size and share design, and design work, across several divisions. Two major business goals are stated by the organization:

- Global re-use of parts

- Scalability in licensing and support through standardization of tools.

As of now, the benefits are defined on a high level. The GlobalCorp COE has defined benefits for the entire organization as such, such as being able to share components across companies. On the division level, each division defines their own business goals. Any formal specifications of user benefits, meaning benefits for the designers at each site, could not be found.

Business Processes. There have been successful efforts on implementing a global New Product Development Process that will serve as the basis for developing inhouse processes. Yet, there has been no specific aim towards supporting design reuse on a process level. Still, a common Engineering Change Management (ECM) process is going to be developed, to manage all parts that are shared. Such high level process is to be developed by the COE in future efforts, when the rest of the architecture is mature.

On the PLM workflow side, standard Product Data Management (PDM) processes such as checking in and out files in the system are governed by the functionality in the 
PDM system ProPDM (masked name). Low level processes related to design reuse are sparsely defined, saved instructions developed in one subsidiary on how to change ownership of a design to another ProPDM instance, so that others may work on it and use it.

Information Architecture. The COE provides the companies that implement ProPDM with an information model that intends to cover their needs for information management. The information model is a specialized version of the out-of-the-box information model of ProPDM, where objects and attributes have been added. Exchanging design is considerably eased by having the same set of information objects, but the instantiation is not standardized, e.g. part numbers differ, causing mapping issues when trying to reuse design. Also, each company is allowed to make additions to the level one data model, in their respective solution for their special needs, but the common ground is still kept thus making collaboration between companies easier. The information model provides no specific support for design reuse apart from providing information objects for ECM.

System Architecture. On the system level, a top level decision was taken to choose ProPDM as their only PLM systems vendor. ProPDM was chosen to be implemented as PLM system for the entire organization with no customizations for the individual divisions. It is however possible to choose which modules to implement - there are also different modules of the information model connected to that - which is seen as configuration rather than customization. The use of the same PLM system eases design reuse, eliminating integration issues on the PDM side.

Although not expressed explicitly by the respondents, there are several other components included in the PLM system architecture. The ERP system is meant to receive information from and communicate to ProPDM. Furthermore, the preferred CAD system is linked to ProPDM through a third-party software. Depending on the discipline in which each company is active, a number of other tools are also integrated, such as Electrical CAD (ECAD) systems and Software Engineering tools.

There is a recommendation for which CAD tool to use (which also comes with a third-party integration software). However, CAD has always been a tender issue; hence it stops at a recommendation of a system, rather than making it mandatory, as with ProPDM. The CAD files are stored in their respective native format, as opposed to using a standard format such as STEP. The ability to reuse CAD data thus depend on who to share with.

\subsection{PLM Implementation Roadmap and Design Reuse Enablers}

Fig. 3 describes what specific solutions, enablers, that address design reuse, and maps them into the different levels of a PLM architecture. Depending on the differing needs, some divisions will leave out steps. So far, all the studied companies are at stage one, laying the foundation for the subsequent stages. Thus, the divisions have not yet been able to harvest the expected benefits of design reuse, which comes with a global pars catalogue and an ECM process. 


\begin{tabular}{|c|c|c|c|c|c|c|c|}
\hline ID & \multicolumn{2}{|l|}{ Action } & & & & & \\
\hline 01 & \multicolumn{2}{|l|}{ Increased design reuse } & & & & & \\
\hline P1 & \multicolumn{2}{|c|}{ Standardised ECM Process } & & & & & $\stackrel{0}{2}$ \\
\hline PW1 & \multicolumn{2}{|c|}{ Standard workflow for check-in checkout } & & & & & 망 \\
\hline PW2 & \multicolumn{2}{|c|}{ Standard workflow for ECM } & & & & & 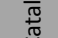 \\
\hline 11 & \multicolumn{2}{|c|}{ Standardized Information objects and attributes } & & & 产 & & $u_{n}$ \\
\hline 12 & \multicolumn{2}{|l|}{ ECM information model } & & & 宸 & & $\frac{\sqrt[t]{\pi}}{\pi^{2}}$ \\
\hline A1 & \multicolumn{2}{|l|}{ Standardized PLM system } & 虽 & & $\sum^{\pi}$ & & $\frac{\sqrt{\pi}}{3}$ \\
\hline A2 & \multicolumn{2}{|c|}{ Recommendation on CAD system } & U̦ & 速 & 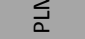 & $\sum_{u}$ & 응 \\
\hline A3 & \multicolumn{2}{|l|}{ Standardized ERP system } & $\frac{t}{0}$ & $\underset{t}{0}$ & 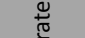 & $\frac{t}{0}$ & $t$ \\
\hline \multirow[t]{6}{*}{ A4 } & \multicolumn{2}{|l|}{ ERP-PLM integration } & $\begin{array}{l}\circ \\
\frac{0}{2} \\
\\
\end{array}$ & $\begin{array}{l}\frac{0}{2} \\
\text { ज } \\
\end{array}$ & 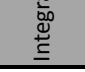 & 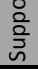 & $\begin{array}{l}\circ \\
\text { ํㅡㄱ } \\
\text { ज }\end{array}$ \\
\hline & & Business Objectives & & & & & \\
\hline & & Processes & & & & & P1 \\
\hline & & PLM Workflows & PW1 & & & & PW2 \\
\hline & & Information Architecture & 11 & & & & 12 \\
\hline & & Applications & $A 1, A 2$ & & $\mathrm{~A} 3, \mathrm{~A} 4$ & & \\
\hline
\end{tabular}

Fig. 3. Implementation roadmap for the PLM solution at GlobalCorp. Each implementation phase is covering global collaboration and design reuse in a certain field, e.g. Mechanical CAD (MCAD) and Electrical CAD (ECAD). Gray areas have enablers.

\subsection{Benefits and Drawbacks with the Solution for Global Design Reuse}

Even though a global parts catalogue managed by an ECM process is the ultimate business goals, there are several benefits to be harvested in a global PLM strategy. Some are connected to the functionality of the PLM system itself, others to the concept of PLM and design reuse. At the same time, several drawbacks have been discovered, both on the implementation side and on the user side. Table 1 and Table 2 list the discovered benefits and drawbacks. The benefits in Table 1 are a mix of actual proved benefits and perks that are yet to be fulfilled - they are estimated to be fulfilled as the project progresses. The drawbacks (Table 2) are generally discovered on the user side, but also by the local PLM management.

\section{Discussion}

As displayed in Table 1 and Table 2, there are several benefits and drawbacks on the way to the final goal of design reuse. Fig. 4 shows that most of the benefits are still in the future, whereas the drawbacks are current. As no subsidiaries have yet reached further than the MCAD vaulting, more drawbacks are to be expected. 
Table 1. List of benefits discovered at GlobalCorp

\begin{tabular}{|ll|}
\hline ID & Benefit \\
\hline B1 & $\begin{array}{l}\text { Better data quality through being able } \\
\text { to control attributes }\end{array}$ \\
\hline B2 & $\begin{array}{l}\text { Easier ROI through standardised support } \\
\text { for it }\end{array}$ \\
\hline B3 & Global sharing of 3D models \\
\hline B4 & Reuse of part numbers \\
\hline B5 & Around-the-clock design work \\
\hline B6 & Single set of information \\
\hline B7 & $\begin{array}{l}\text { Automated approval processes for } \\
\text { reviewing new and changed 3D models }\end{array}$ \\
\hline B8 & $\begin{array}{l}\text { Design reuse through global parts } \\
\text { catalogue }\end{array}$ \\
\hline B9 & $\begin{array}{l}\text { Control of engineering changes, and } \\
\text { how it affects other divisions }\end{array}$ \\
\hline B10 & $\begin{array}{l}\text { Reduced licensing cost through global } \\
\text { licensing }\end{array}$ \\
\hline B11 & $\begin{array}{l}\text { Global cooperation with security } \\
\text { managed by the system }\end{array}$ \\
\hline B12 & $\begin{array}{l}\text { Lower implementation time and effort } \\
\text { due to standard deployment model }\end{array}$ \\
\hline B13 & $\begin{array}{l}\text { Faster being able to find the right } \\
\text { information through version } \\
\text { management }\end{array}$ \\
\hline
\end{tabular}

Table 2. List of current drawbacks discovered at GlobalCorp

\begin{tabular}{|ll|}
\hline ID & Drawback \\
\hline D1 & $\begin{array}{l}\text { No implementation support for the non- } \\
\text { standard solution }\end{array}$ \\
\hline D2 & $\begin{array}{l}\text { Missing functionality in the system is } \\
\text { hard to fix and must be implemented by } \\
\text { the vendor }\end{array}$ \\
\hline D3 & $\begin{array}{l}\text { ProPDM misses support for core } \\
\text { disciplines for sharing designs }\end{array}$ \\
\hline D4 & $\begin{array}{l}\text { Divisions in the forefront of the } \\
\text { implementation have to pave the } \\
\text { ground and take all the hits }\end{array}$ \\
\hline D5 & $\begin{array}{l}\text { System performance for exchanging of } \\
\text { 3D drawings is low }\end{array}$ \\
\hline D6 & $\begin{array}{l}\text { Data sharing abilities varies from } \\
\text { instance to instance }\end{array}$ \\
\hline D7 & $\begin{array}{l}\text { End users have insufficient knowledge } \\
\text { about how to use the system }\end{array}$ \\
\hline Lack of support for security \\
D13
\end{tabular}

\subsection{Future Benefits and Immediate Drawbacks}

The results show that it does not only take time to implement PLM, but also that the real benefits are long term. Furthermore, the benefits along the way are next to none, there are in fact several drawbacks that may jeopardize the entire PLM effort as such - for example, ProPDM misses support for core disciplines for sharing designs in Table 2 affects eight of the thirteen discovered benefits (see Fig. 5). IT projects have to compete with other investments. Many businesses focus on short term return on investments, causing large strategic IT-projects to fall under the axe of quick wins[20]. PLM projects shall not focus on short-term wins, but in order to survive and drive the change process, they have to consider them. Short-term wins is also proven to keep the organization's motivation up throughout the change [21]. In an economy where quarterly revenues are the factor that governs what projects to support, even 


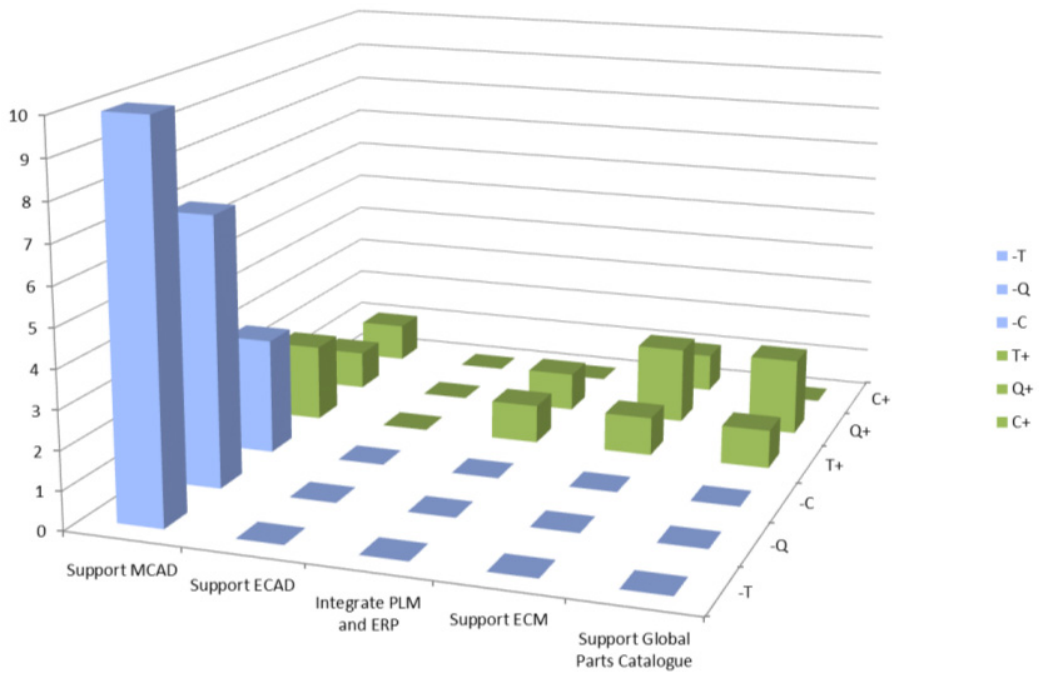

Fig. 4. The Benefits and drawbacks are estimated to effect the development time (T), product quality $(\mathrm{Q})$ and product cost $(\mathrm{C})$ in a positive way, or negative. The hight of the bars represent the number of benefits (green) and drabacks (blue) in each category and implementation phase.

strategic projects must show benefits fast. Projects showing negative short term result will have little chance of surviving. Consequently, drawbacks cannot be overlooked with the argument that they will be outshone by the future benefits, they need to be managed. To manage the problem, companies need to define benefits for all phases in the implementation project.

\subsection{Lack of Enablers on All Architecture Levels}

Fig. 4 shows the estimated effect on cost, time and quality of the benefits and drawbacks. Even though the bars only represent the number of benefits and drawbacks for each category and implementation phase - thus each benefit and drawback is accounted for equally - it still gives an indication of that the development time is heavily affected by the implementation. As the implementation progresses to ECAD vaulting, it is reasonable to assume that new drawbacks will arise, and that old drawbacks will persist. It is clear that the user find themselves in a situation where they are not as efficient as they need to be.

Several of the drawbacks (e.g. D6, D7, D9 and D10) relate to lack of or unclear processes, both on a high level (design reuse as a part of the development process) and a lower level (design guidelines on how to reuse and design for reuse). The findings show that though the PLM architecture is rich in enablers in the application architecture, it is alarmingly sparse (see Fig. 3) when it comes to processes. The workarounds - such as instructions for changing ownership of a part - implicitly suggests that design reuse is possible, but the process is not standardized, nor is it used consequently throughout the organization. To fully support design reuse there is a need to identify enablers on all PLM architecture levels. There must be a clear link between 
the different levels in the PLM architecture. As processes are the core of development, the information architecture needs to support the processes. In turn, the application architecture shall support the information need and information flow, as agreed by both Eppinger [12] and Zimmerman [9]. If no processes are defined, specifying the application architecture is a walk in the dark.

In more general terms, enablers must be defined on all architecture levels and there needs to be traceability between the enablers on the different levels, from business objectives through processes, and information architecture down to applications.

\subsection{Relations between Benefits and Drawbacks}

All drawbacks will not jeopardize the implementation of all benefits. Fig. 5 describes the relation between the drawbacks and benefits. The number 1 in a cell marks that a particular drawback can influence the realization of that particular benefit. The figure displays the partitioned DSM of the drawbacks and benefits where two distinct areas can be seen. The lower right area constitutes the benefits and drawbacks associated with the implementation of the system, which apparently are decoupled from the rest, and could be managed without influencing the other parameters. The large gray area in the upper left corner of the matrix is composed by benefits and drawbacks associated with the functionality - and the lack thereof - of the architecture. Here, the parameters are so coupled that any distinct phases are hard to determine. Knowing the relations between benefits and associated drawbacks is a necessity in order to be able to define credible phases of implementation, which in turn, is a necessity in order to be able to define benefits for all phases of the implementation.

The benefits and drawbacks are project specific. Even so, it is important to acknowledge that there are drawbacks associated to the embodiment of the benefits. To gain benefits one needs to manage the drawbacks, and manage them before they occur. Brainstorming together with DSMs can be one way of being able to plan for benefits in all phases of the project.

The conclusion that distant benefits and present drawbacks may jeopardize the future of the project is found in other research in general, or in Berle's, Devaraj's Kotter's work [20-22]. GlobalCorp recognized the organizational change as one of the toughest challenges. The importance to define benefits for all phases was verified through interviews with the COE where they stated that it is vital. The presentation of the result generated discussions of the numbers of benefits compared to the drawbacks. Again, the benefits and drawbacks are not quantified, but give a rough picture on the impact on time, quality and cost. The representatives agreed on the result of the analysis, also stating that there may be even more drawbacks to expect as the projects progress.

\subsection{There Is More to Design Reuse Than Just Reusing Parts}

The potential benefits of design reuse and support through PLM stretches beyond reusing parts and CAD models. PLM can be used to facilitate design reuse in terms of larger subsystems or sharing technologies. An organization as diverse as GlobalCorp 


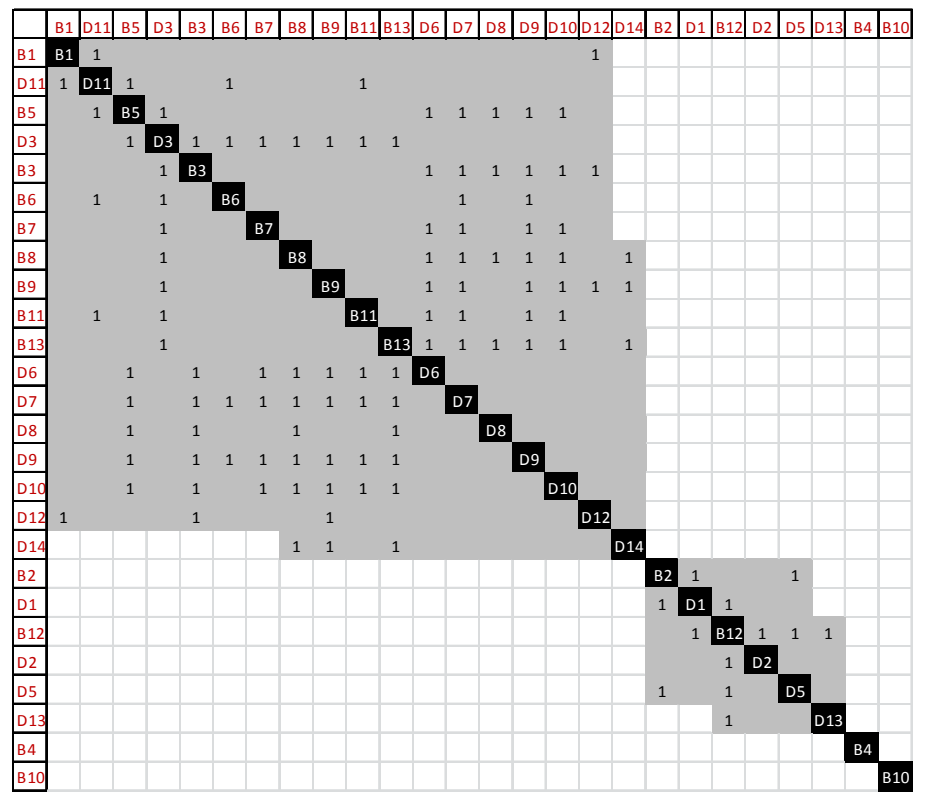

Fig. 5. An inter-domain dependency structure matrix [23] mapping dependency between benefits and drawbacks. A cell with the number 1 denotes that the drawback may affect the potential benefit negatively. The matrix is partitioned, and the partitions marked in gray.

may gain from adopting a wider approach to design reuse. There are, for example, several technology areas where one subsidiary within GlobalCorp has superior knowledge. Similar technology is used at other subsidiaries, but no technology knowledge is shared. In this sense, sharing technology becomes more about sharing know-how, than sharing parts. There is support for such design reuse that can be incorporated in the PLM architecture [24].

Part and subsystem sharing is better suited for subsidiaries that manages to find true commonality that does not restrain them from delivering desired performance of the product to their specific customers. In the same way, a common IT environment can aid the development process in those cases where collaboration is possible, but also restrains it from being optimized to each subsidiary's needs.

\section{Conclusions}

The study shows that GlobalCorps approach to support design reuse has many possible benefits - around-the-clock design work, design reuse through global parts catalogue and control of engineering changes just to name a few -, but also that there are gaps in the PLM architecture. Many of the benefits are long term, and the short term benefits that work as a driver for the change can be conspicuous by their absence. Furthermore, the implementation of a solution does come with a number of drawbacks. These drawbacks need to be managed in order for them to not jeopardize the realization of the benefits. 
If it shall be possible at all to define benefits for all phases in the project, work need to be put into defining those stages so that it is possible to implement the benefits without having them sabotaged with unforeseen drawbacks. The approach used in the analysis in this paper is one possibility to map the dependencies between potential benefits and possible drawbacks. Using such an approach does require that drawbacks can actually be predicted, which is not always the case. Experienced PLM experts and engineers should however add up to a strong group when it comes to defining both benefits and drawbacks. For example, Garetti [25] suggest involving users in early brainstorming sessions to identify drawbacks with a proposed PLM approach. The approach is verified and validated through interviews with PLM experts, but its effects on an actual implementation projects remains to be explored. Further, GlobalCorp is a common company in size, their experience in PLM, and organization. The discovered phenomena are likely to be found in several cases.

Perhaps even more important to stress is the fact that full support for design reuse requires enablers on all levels of the PLM architecture. As the core of product development is its processes, these need to be carefully mapped before they can be supported by any application architecture. Further, design reuse is more than just reusing parts. Commonality can be found in for example technologies which are more easily shared throughout a diverse organization.

To summarize, if implementing PLM for design reuse it is important to:

- Find commonality where it exists, and support that, rather than support collaboration everywhere.

- Identify enablers on all PLM architecture levels, and the links between the levels.

- Define credible benefits for all phases, and manage the associated drawbacks.

Acknowledgements. This work was carried out at the Wingquist Laboratory VINN Excellence Centre within the Area of Advance - Production at Chalmers, supported by the Swedish Governmental Agency for Innovation Systems (VINNOVA). The support is gratefully acknowledged. Also, we would sincerely like to thank the interviewees and the management at GlobalCorp that made this possible. Your time and expertise is most appreciated.

\section{References}

1. Jiao, J., Simpson, T.W., Siddique, Z.: Product family design and platform-based product development: a state-of-the-art review. J. Intell. Manuf. 18(1), 1-3 (2007)

2. Meyer, M.H., Lehnerd, A.P.: The power of product platforms: building value and cost leadership. Free Press, New York (1997)

3. Robertson, D., Ulrich, K.: Planning for product platforms. Sloan Manage. Rev., 39(4), 19-+ (1998)

4. Svensson, D., Malmström, J., Pikosz, P., Malmqvist, J.: A Framework for Modelling and Analysis of Engineering Information Systems. In: ASME Design Engineering Technical Conferences, Las Vegas, Nevada, USA (1999)

5. CIMdata, Product Lifecycle Management (PLM) Definition (2010), http://www. cimdata.com/plm/definition.html 
6. Hewett, A.: Product Lifecycle Management (PLM): Critical Issues and Challenges in Implementation. In: Nambisan, S. (ed.) Information Technology and Product Development, pp. 81-105. Springer, US (2009)

7. Kota, S., Sethuraman, K.: Managing Variety in Product Families Through Design for Commonality. In: ASME, Design Theory and Methodology - DTM 1998, Atlanta, GA, USA (1998)

8. Stark, J.: Product lifecycle management: 21 st century paradigm for product realisation. Springer, London (2005)

9. Zimmerman, T.: Implementing PLM Across Organisations, PhD thesis, Chalmers University of Technology, Gothenburg (2008)

10. Sudarsan, R., Fenves, S.J., Sriram, R.D., Wang, F.: A product information modeling framework for product lifecycle management. Computer-Aided Design 37(13), 1399-1411 (2005)

11. Eppinger, S.D., Chitkara, A.R.: The Practice of Global Product Development. Mit Sloan Manage Rev., November 21 (2009)

12. Eppinger, S.D.: Innovation at the Speed of Information. Harvard Bus. Rev., 79(part 1), 149-158 (2001)

13. Simpson, T.W.: Product platform design and customization: Status and promise. Ai Edam 18(1), 3-20 (2004)

14. Corin Stig, D., Bergsjö, D.: Means for Internal Knowledge Reuse in Pre-Development the Technology Platform Approach. In: International Conference on Engineering Design, ICED 2011, Copenhagen, Denmark (2011)

15. Bokinge, M., Malmqvist, J.: PLM Implementations Guidelines - Relevance and Application in Practice: A Discussion of Findings from a Pretrospective Case Study. Accepted to: International Journal of Product Lifecycle Management (2012)

16. Abramovici, M.: Status and Development Trends of Product Lifecycle Management Systems. In: Proc. Proceeding of International Conference on Integrated Product and Process Development

17. Blessing, L.T.M., Chakrabarti, A.: DRM, a Design Research Methodology. Springer, London (2009)

18. Maxwell, J.A.: Qualitative research design: an interative approach. Sage, Thousand Oaks (1996)

19. Yin, R.K.: Case study research: design and methods. SAGE, Thousand Oaks (2003)

20. Devaraj, S., Kohli, R.: The IT payoff: measuring the business value of information technology investments. Financial Times Prentice Hall, New York (2002)

21. Kotter, J.P.: Leading change. Harvard Business School Press, Boston (1996)

22. Berle, A.: PLM Development and Implementation at Volvo 3P, using Catia V5 and Enovia V5. In: 1st Nordic Conference on Product Lifecycle Management, Göteborg, Sweden (2006)

23. Malmqvist, J.: A classification of matrix-based methods for product modeling. In: DESIGN 2002: Proceedings of the 7th International Design Conference, vol. 1 and 2, pp. 203-210 (2002)

24. Bergsjö, D.: Process and it Support for Technology Platform Development and Use. In: Proc. Proceedings of IAMOT (2011)

25. Garetti, M.: Organisational change and knowledge management in PLM implementation. International Journal of Product Lifecycle Management 1(1), 43 (2005) 